\title{
Perbandingan Algoritma Naive Bayes Dan Support Vector Machine Dalam Seleksi Kelulusan Pemberkasan Beasiswa BPP-PPA Fakultas Teknik Universitas Negeri Jakarta
}

\author{
Fakhriyani , Widodo , Bambang Prasetya Adhi ${ }^{2}$ \\ 1,2,3 Pendidikan Teknik Informatika dan Komputer Fakultas Teknik \\ Universitas Negeri Jakarta \\ fanybroto@gmail.com, widodo@unj.ac.id, bambangpadhi@unj.ac.id
}

\begin{abstract}
ABSTRAK
Beasiswa merupakan salah satu program untuk membantu meringankan mahasiswa dalam membayar uang kuliah, namun sering terjadi kesalahan dalam pemberian beasiswa tersebut karena masih dilakukan secara manual dan tidak adanya kriteria yang jelas bagaimana seorang mahasiswa dapat memperoleh beasiswa. Untuk mengantisipasi agar tidak terjadinya kesalahan dalam pemberian beasiswa maka dibutuhkan sebuah Sistem Pendukung Keputusan, namun sebelum dilakukan pembuatan sistem tersebut dirasa perlu untuk mengetahui algoritma terbaik untuk menyeleksi berkas beasiswa tersebut. Penelitian ini menggunakan dua algoritma Data Mining yaitu algoritma Nä̈ve Bayes dan Support Vector Machine. Naïve Bayes merupakan metode pengklasifikasian yang dapat digunakan untuk memprediksi probabilitas keanggotaan suatu class berdasarkan pengalaman di masa sebelumnya dengan kondisi antar atribut saling bebas. Support Vector Machine adalah sebuah metode prediksi dalam klasifikasi yang dapat dilakukan pada kasus yang secara linier dapat dipisahkan, maupun non-linier dengan menggunakan konsep kernel pada ruang kerja berdimensi tinggi. Data mahasiswa yang lulus dan tidak lulus seleksi berkas beasiswa BPP-PPA akan diolah menggunakan algoritma Nä̈ve Bayes dan Support Vector Machine. Setelah diklasifikasi kedua algoritma tersebut akan dihitung hasil akurasinya menggunakan $K$-fold Cross Validation. Berdasarkan hasil contoh kasus seleksi menunjukan bahwa hasil perhitungan akurasi algoritma Nä̈ve Bayes adalah 0.7542, sedangkan hasil akurasi algoritma Support Vector Machine adalah 0.99. Kedua sistem telah mampu menangani proses penyeleksian kelulusan pemberkasan beasiswa BPP-PPA Fakultas Teknik Universitas Negeri Jakarta. Algoritma Support Vector Machine menghasilkan rata-rata akurasi 0.99 yang mendekati 1, maka algoritma tersebut dinilai lebih akurat dan direkomendasikan untuk penelitian selanjutnya.
\end{abstract}

Kata Kunci: Data Mining, Beasiswa, Akurasi, Naïve Bayes, Support Vector Machine.

1. Pendahuluan

Latar Belakang

Beasiswa adalah tunjangan uang yang diberikan kepada pelajar atau mahasiswa sebagai bantuan biaya belajar ${ }^{1}$. Pemberian beasiswa dapat dikategorikan sebagai pemberian cuma-cuma maupun pemberian pada ikatan kerja (ikatan dinas)

\footnotetext{
${ }^{1}$ Departemen Pendidikan Nasional, Kamus Besar Bahasa Indonesia Edisi Ketiga. (Jakarta: Balai Pustaka,2005), hlm. 89.
}

setelah selesainya pendidikan. Tujuan dari diberikannya beasiswa adalah untuk membantu para pelajar atau mahasiswa dalam mengantisipasi mahalnya memperoleh pendidikan sehingga pelajar tersebut dapat memenuhi segala kebutuhan dalam proses belajar agar pendidikan dapat terlaksana dengan baik. Beasiswa dapat diberikan oleh lembaga pemerintah, perusahaan, ataupun yayasan.

Salah satu penyelenggara beasiswa di lembaga pemerintah adalah Direktorat Jenderal Pembelajaran dan Kemahasiswaan Kementerian Riset, Teknologi, dan Pendidikan Tinggi. Program beasiswa yang 
dibeikan oleh DIKTI adalah Beasiswa Peningkatan Prestasi Akademik (Beasiswa-PPA) dan Beasiswa Bantuan Biaya Pendidikan Peningkatan Prestasi Akademik (BPP-PPA). Bantuan biaya pendidikan tersebut diberikan kepada mahasiswa yang orang tuanya tidak mampu untuk membiayai pendidikannya, dan kepada mahasiswa yang mempunyai prestasi tinggi, baik kurikuler maupun ekstrakulikuler ${ }^{2}$.

Universitas Negeri Jakarta menjadi salah satu universitas yang bekerja sama dengan DIKTI dalam menyelenggarakan beasiswa BPP-PPA. Saat ini fakultas teknik masih menggunakan cara manual untuk menentukan mahasiswa yang berhak menerima beasiswa BPP-PPA. Sehingga rawan akan kesalahan seperti human error dan pemberian beasiswa tidak tepat sasaran. Kemudian pengolahan data kurang efektif, membutuhkan waktu yang relatif lama, dan sering terjadi subjektifitas dari para pengambil keputusan ataupun kecurangankecurangan lain yang dapat terjadi pada pemberian beasiswa BPP-PPA.

Agar tidak terjadi kesalahan dan untuk mempermudah para petugas fakultas dalam menyeleksi dan menentukan mahasiswa yang berhak menerima beasiswa BPP-PPA, maka diperlukan sebuah Sistem Pendukung Keputusan yang berfungsi untuk membantu melakukan seleksi kepada para calon penerima beasiswa. Namun sebelum dibuatnya Sistem Pendukung Keputusan diperlukan perencanaan yang baik, salah satunya dengan pemilihan algoritma yang digunakan oleh sistem nanti.

Terdapat banyak algoritma pada Data Mining yang bisa digunakan pada penelitian ini, namun diantara banyaknya algoritma tersebut penulis memilih dua algoritma yaitu algoritma Nä̈ve Bayes dan algoritma Support Vector Machine. Penulis memilih untuk membandingkan algoritma Nä̈ve Bayes dan Support Vector Machine dikarenakan kedua algoritma tersebut termasuk dalam dua dari sepuluh algoritma terbaik.

Alasan penulis membandingkan kedua algoritma tersebut karena belum ada penelitian yang menggunakan algoritma Nä̈ve Bayes dan Support Vector Machine untuk kasus seleksi berkas beasiswa BPP-PPA. Kedua algoritma tersebut penulis pilih karena merupakan algoritma klasifikasi pada Data Mining. Kemudian kedua algoritma tersebut menggunakan dua teknik yang berbeda, untuk algoritma Nä̈ve Bayes menggunakan teknik statistik sedangkan Support Vector Machine menggunakan teknik machine learning.

\footnotetext{
${ }^{2}$ Direktorat Jendral Pendidikan Tinggi, Pedoman Umum Beasiswa Bantuan Biaya Pendidikan Peningkatan Prestasi Akademik (PPA), (Direktorat Jendral Pembelajaran dan Kemahasiswaan Kementerian Riset, Teknologi, dan Pendidikan Tinggi, 2015), hlm. i.
}

Perbandingan algoritma Nä̈ve Bayes dan Support Vector Machine dilakukan untuk mencari algoritma yang lebih akurat pada kasus seleksi berkas beasiswa BPP-PPA. Penulis menggunakan data pendaftar dan penerima beasiswa BPP-PPA Fakultas Teknik Universitas Negeri Jakarta tahun 2011 hingga tahun 2015 untuk kepentingan perbandingan algoritma. Setelah diketahui algoritma yang lebih akurat dan tepat untuk seleksi berkas beasiswa BPP-PPA diharapkan dapat membantu pembuatan Sistem Pendukung Keputusan pada penelitian selanjutnya.

Berdasarkan penjelasan diatas maka Penulis tertarik untuk mencoba memecahkan masalah yang ada khususnya di bidang penyeleksian berkas beasiswa. Hal ini yang mendorong Penulis untuk mencoba menganalisa "Perbandingan Algoritma Nä̈ve Bayes dan Support Vector Machine dalam Seleksi Kelulusan Pemberkasaan Beasiswa BPPPPA Fakultas Teknik Universitas Negeri Jakarta"

\section{Dasar Teori}

\subsection{Data Mining}

Data Mining adalah proses menemukan pola yang menarik dan pengetahuan dari sejumlah data yang besar. Sumber data bisa termasuk databases, data warehouses, theWeb, repositori informasi lainnya, atau data yang mengalir ke dalam sistem secara dinamis ${ }^{3}$.

Data Mining merupakan teknologi yang menggabungkan metoda analisis tradisional dengan algoritma yang canggih untuk memproses data dengan volume besar. Data mining adalah suatu istilah yang digunakan untuk menemukan pengetahuan yang tersembunyi di dalam database. Data mining merupakan proses semi otomatik yang menggunakan teknik statistik, matematika, kecerdasan buatan, dan machine learning untuk mengekstraksi dan mengidentifikasi informasi pengetahuan potensial dan berguna yang bermanfaat yang tersimpan di dalam database besar ${ }^{4}$.

Berdasarkan dari teori para ahli diatas dapat disimpulkan bahwa Data Mining adalah sebuah teknik untuk mencari pola dalam sebuah kumpulan data yang sangat besar. Teknik yang digunakan antara lain teknik statistik, matematika, kecerdasan buatan dan machine learning. Data Mining menganalisis kumpulan data yang sebelumnya hanya disimpan pada database menjadi sebuah pengetahuan yang bermanfaat.

\subsection{Klasifikasi}

Klasifikasi adalah suatu bentuk analisis data yang mengekstrak model dan menggambarkan kelas

\footnotetext{
${ }^{3}$ Jiawei Han, dkk., Data Mining Concepts and Techniques, $3^{r d} e d$. (Waltham, USA: Elsevier Inc., 2012), hlm. 8 .

${ }^{4}$ Turban E, dkk., Decicion Support Systems and Intelligent Systems. (Yogyakarta:Andi Offset,2005), hlm. 23.
} 
data penting. Seperti model-model, disebut classifiers, memprediksi kategoris (tidak beraturan) kelas label ${ }^{5}$

Klasifikasi data adalah dua tahap proses, terdiri dari tahap belajar (learning step) dimana model klasifikasi dibangun dan tahap klasifikasi dimana model yang digunakan untuk memprediksi label kelas untuk data yang diberikan ${ }^{6}$.

Berdasarkan teori para ahli diatas dapat disimpulkan klasifikasi adalah proses pengelompokkan suatu data ke dalam beberapa kelas data. Pengelompokkan data tersebut dilakukan melalui tahap pembelajaran dimana data-data tersebut dianalisis, kemudian tahap klasifikasi untuk memisahkan data ke dalam kelas yang dianggap sesuai dengan kriteria data tersebut.

Pada dasarnya klasifikasi dibagi menjadi dua, rule based classification dan non rule based classification. Pada penulisan kali ini salah satu algoritma yang digunakan adalah Nä̈ve Bayes yang termasuk dalam salah satu non rule based classification.

Nä̈ve Bayes merupakan salah satu penerapan teorama Bayes. Naïve Bayes didasarkan pada asumsi penyederhanaan bahwa nilai atribut secara kondisional saling bebas jika diberikan nilai output ${ }^{7}$.

Nä̈ve Bayes adalah pengklasifikasian statistik yang dapat digunakan untuk memprediksi probabilitas keanggotaan suatu class $^{8}$.

Formula umum untuk prediksi Bayes didasari oleh teorama Bayes adalah sebagai berikut:

$$
P(H \mid X)=\frac{P(X \mid H) P(H)}{P(X)}
$$

Keterangan :

$\mathrm{X} \quad$ : Data dengan class yang belum diketahui

$\mathrm{H} \quad$ : Hipotesis data X merupakan suatu class spesifik

$\mathrm{P}(\mathrm{H} \mid \mathrm{X})$ : Probabilitas hipotesis $\mathrm{H}$ berdasar kondisi $\mathrm{X}$ (posteriori probability)

$\mathrm{P}(\mathrm{H}) \quad$ : Probabilitas hipotesis $\mathrm{H}$ (prior probability)

$\mathrm{P}(\mathrm{X} \mid \mathrm{H})$ : Probabilitas X berdasarkan kondisi pada hipotesis $\mathrm{H}$

$\mathrm{P}(\mathrm{X}) \quad$ : Probabilitas X

\footnotetext{
${ }^{5}$ Jiawei Han, dkk., Data Mining Concepts and Techniques, $3^{r d}$ ed. (Waltham, USA: Elsevier Inc., 2012), hlm. 327.

${ }^{6}$ Ibid, h. 328

${ }^{7}$ Khafiizh Hastuti, Analisis Komparasi Algoritma Klasifikasi Data Mining untuk Prediksi Mahasiswa Non Aktif. (Seminar Nasional Teknologi Informasi dan Komunikasi Terapan, 2012), hlm. 243.

${ }^{8}$ Eko Prasetyo, Data Mining : Konsep dan Aplikasi menggunakan MATLAB, 1st ed. (Yogyakarta:Andi Offset, 2012), hlm. 37.
}

\subsection{Support Vector Machine}

SVM adalah sebuah metode untuk klasifikasi baik data linear maupun nonlinear. SVM merupakan algoritma yang bekerja sebagai berikut. Menggunakan pemetaan nonlinear untuk mengubah data pelatihan asli ke dimensi yang lebih tinggi. Dalam dimensi baru ini, akan mencari linear yang optimal untuk memisahkan hyperplane (yaitu, "batas keputusan" yang memisahkan tupel dari satu kelas ke kelas lainnya). Dengan pemetaan nonlinear yang tepat untuk dimensi yang cukup tinggi, data dari dua kelas selalu dapat dipisahkan dengan hyperplane. SVM menentukan hyperplane menggunakan vektor dukungan (tupel pelatihan "penting") dan margin (didefinisikan oleh vektor dukungan) ${ }^{9}$.

SVM memiliki prinsip dasar linear classifier yaitu kasus klasifikasi yang secara linier dapat dipisahkan, namun SVM telah dikembangkan agar dapat bekerja pada problem nonlinear dengan memasukkan konsep kernel pada ruang kerja berdimensi tinggi. Pada ruang berdimensi tinggi, akan dicari hyperplane yang dapat memaksimalkan jarak (margin) antara kelas data ${ }^{10}$.

Berdasarkan teori parah ahli diatas dapat disimpulkan Support Vector Machine adalah sebuah metode klasifikasi untuk data linear maupun nonlinear menggunakan hyperlane pembatas. Pada kasus data nonlinear konsep yang digunakan adalah konsep kernel dengan ruang kerja berdimensi tinggi. Hyperlane pembatas terbaik dapat ditentukan dengan mencari support vector dan maximum margin, kemudian data tersebut akan dipisahkan sesuai dengan hyperlane yang sudah ditentukan.

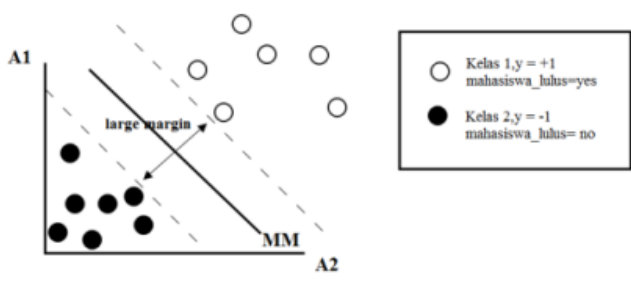

Gambar 2.1 Pemisahan 2 Kelas Data dengan Maximum Margin

Pada Gambar 2.1, SVM menemukan hyperplane pemisah maksimum, yaitu hyperplane yang mempunyai jarak maksimum antara tupel pelatihan terdekat. Support vector ditunjukkan dengan batasan tebal pada titik tupel.

\footnotetext{
${ }^{9}$ Jiawei Han, dkk., Data Mining Concepts and

Techniques, $3^{\text {rd }}$ ed. (Waltham, USA: Elsevier Inc., 2012), hlm. 408.

${ }^{10}$ Pusphita Anna, Penerapan Metode Klasifikasi Support Vector Machine (SVM) pada Data Akreditasi Sekolah Dasar (SD) di Kabupatern Magelang. (Seminar Nasional Informatika, 2014), hlm. 812.
} 


\subsection{Beasiswa Bantuan Biaya Pendidikan} Peningkatan Prestasi Akademik (BPP-PPA)

Sejak tahun 2012 istilah Beasiswa Peningkatan Prestasi Akademik (PPA) dan Bantuan Belajar Mahasiswa (BBM) disesuaikan dengan istilah yang sejalan dengan ketentuan yang ada yaitu menjadi Beasiswa Peningkatan Prestasi Akademik (Beasiswa-PPA) dan Bantuan Biaya Pendidikan Peningkatan Prestasi Akademik (BPP-PPA). Beasiswa Bantuan Biaya Pendidikan Peningkatan Prestasi Akademik (BPP-PPA) adalah salah satu beasiswa yang diberikan oleh Pemerintah melalui Direktorat Jenderal Pembelajaran dan Kemahasiswaan Kementerian Riset, Teknologi, dan Pendidikan Tinggi. Bantuan biaya pendidikan tersebut diberikan kepada mahasiswa yang orang tuanya tidak mampu untuk membiayai pendidikannya, dan kepada mahasiswa yang mempunyai prestasi tinggi, baik kurikuler maupun ekstrakulikuler ${ }^{11}$.

\subsection{K-fold Cross Validation}

Bentuk umum pendekatan ini disebut dengan $K$ fold Cross Validation, yang memecah set data menjadi k bagian set data dengan ukuran yang sama. Setiap kali berjalan, satu pecahan berperan sebagai set data uji sedangkan pecahan lainnya menjadi set data latih. Prosedur tersebut dilakukan sebanyak k kali sehingga setiap data berkesempatan menjadi data uji tepat satu kali dan menjadi data latih sebanyak k-1 kali. Total error didapatkan dengan menjumlah semua error yang didapatkan dari k kali proses $^{12}$.

Dataset training secara acak dibagi menjadi $\mathrm{K}$ dataset dengan ukuran yang sama dimana setiap bagian memiliki kurang lebih distribusi class yang sama. Classifier dilatih k-kali, setiap waktu dengan set yang berbeda dan dikeluarkan untuk dataset tes. Diperkirakan kesalahan adalah mean dari kkesalahan $^{13}$.

Berdasarkan teori para ahli diatas dapat disimpulkan bahwa dalam teknik $K$-fold Cross Validation dataset dibagi menjadi 10 partisi secara acak, kemudian dilakukan sejumlah 10 kali eksperimen dimana masing-masing eksperimen menggunakan data partisi ke-10 sebagai data teseting dan memanfaatkan sisa partisi lainnya sebagai data training. Untuk 1 iterasi dilakukan 10

${ }^{11}$ Direktorat Jendral Pendidikan Tinggi, Pedoman Umum Beasiswa Bantuan Biaya Pendidikan Peningkatan

Prestasi Akademik (PPA), (Direktorat Jendral

Pembelajaran dan Kemahasiswaan Kementerian Riset,

Teknologi, dan Pendidikan Tinggi, 2015), hlm. i.

${ }^{12}$ Eko Prasetyo, DATA MINING - Mengolah Data menjadi Informasi Menggunakan Matlab, (Yogyakarta: Andi Offset, 2014), hlm. 264.

${ }^{13}$ Ron Kohavi, A Study of Cross-Validation and Bootstrap for Accuracy Estimation and Model Selection.

(International Joint Conference on Artifical Intellegence), hlm. 2. kali pengulangan (1-st fold, 2-nd fold,.....10-th fold) dengan 10 klasifikasi dimana 1 data testing dan 9 data training secara bergantian.

\section{Metodologi}

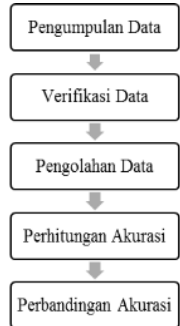

Gambar 3.1 Diagram Alir Penelitian

Berdasarkan Gambar 3.1 Langkah pertama dalam penelitian adalah pengumpulan data. Penulis mendapatkan soft copy 500 data mahasiswa yang lulus dan 200 data mahasiswa tidak lulus seleksi pemberkasan beasiswa BPPPPA Fakultas Teknik Universitas Negeri Jakarta tahun 2011-2015.

Setelah data terkumpul dan mencukupi kebutuhan penelitian maka langkah selanjutnya adalah verifikasi data. Pada tahap verifikasi data ini terdapat tiga proses yaitu, pertama proses perubahan data sesuai parameter, kedua proses perubahan data ke dalam bentuk vektor, proses ketiga adalah pemberian label pada masingmasing vektor data. Untuk data mahasiswa yang lulus seleksi berkas diberikan label angka 1, sedangkan untuk data mahasiswa yang tidak lulus seleksi berkas diberikan label angka 0 . Setelah 3 proses tersebut dilakukan maka akan masuk ke tahap selanjutnya yaitu tahap pengolahan data.

Pada tahap pengolahan data penulis merancang penelitian yang akan dilakukan seperti ilustrasi pada Gambar 3.2 berikut.

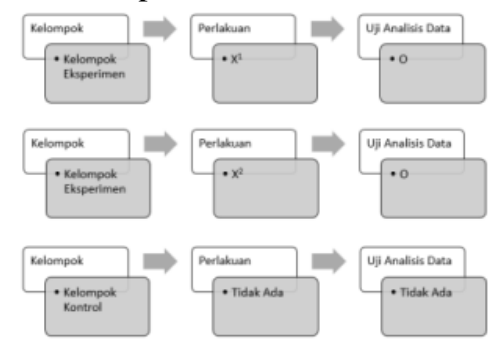

Gambar 3.2 Rancangan Penelitian

Keterangan :

KE : Kelompok Eksperimen

KK : Kelompok Kontrol

$\mathrm{X}^{1} \quad$ : Klasifikasi data menggunakan algoritma Nä̈ve Bayes

$\mathrm{X}^{2} \quad$ : Klasifikasi data menggunakan Algoritma SVM

$\mathrm{O} \quad$ : Evaluasi hasil akurasi algoritma menggunakan metode $K$-fold Cross Validation 
Berdasarkan Gambar 3.2 diatas, penelitian ini melibatkan dua kelompok data yaitu kelompok eksperimen dan kelompok kontrol. Hanya satu kelompok saja yang diberikan perlakuan yaitu kelompok eksperimen yang diolah menggunakan dua algoritma (algoritma Nä̈ve Bayes dan Support Vector Machine). Sedangkan kelas kontrol tidak diolah menggunakan dua algoritma atau tidak diberikan perlakuan apapun.

Baik kelas eksperimen maupun kelas kontrol keduanya berasal dari sumber data yang sama, yaitu data mahasiswa yang lulus maupun tidak lulus seleksi berkas beasiswa BPP-PPA tahun 2011-2015 di Fakultas Teknik Universitas Negeri Jakarta. Perbedaannya adalah pada kelas eksperimen data yang sama akan diproses menggunakan dua algoritma yang berbeda.

\section{Hasil dan Analisis}

\subsection{Deskripsi Hasil Penelitian}

Data pendaftar beasiswa BPP-PPA yang dikumpulkan oleh penulis sebanyak 500 data mahasiswa yang lulus pemberkasan dan 200 data mahasiswa yang tidak lulus pemberkasan. Adapun syarat dan kriteria yang penulis simpulkan melalui data yang didapatkan, buku pedoman beasiswa BPPPPA serta kebijakan Universitas Negeri Jakarta untuk menentukan lulus atau tidaknya mahasiswa pendaftar beasiswa BPP-PPA adalah sebagai berikut:

a. IPK minimal 2,75

b. Gaji orang tua minim atau kecil

c. Rekening listrik dibawah 2200v

d. Surat Keterangan Tidak Mampu (SKTM) dari pihak kelurahaan yang akan mempengaruhi kelengkapan berkas dari mahasiswa tersebut.

\subsubsection{Verifikasi Data}

Sebelum data diproses menggunakan algoritma Nä̈ve Bayes dan Support Vector Machine maka data tersebut harus diverifikasi terlebih dahulu. Verifikasi data dilakukan guna mengurangi kesalahan pemrosesan data pada saat dilaksanakannya eksperimen dan format data sesuai dengan kebutuhan penelitian.

\subsubsection{Proses Perubahan Data Sesuai Parameter} Tabel 4.1 Potongan Data Inti yang Sudah Dipersempit

\begin{tabular}{c|l|c|c|c|c|}
\hline \multirow{2}{*}{ No } & N a m a & IPK & $\begin{array}{c}\text { Daya Listrik } \\
\text { (Volt) }\end{array}$ & $\begin{array}{c}\text { Penerbit } \\
\text { SKTM }\end{array}$ & Gaji \\
\hline 1 & Fathudin & 2.79 & 1300 & Lurah & $\operatorname{Rp~} 1,500,000$ \\
\hline 2 & Okky Andri Yanto & 3.25 & 1300 & Lurah & $\operatorname{Rp~} 1,500,000$ \\
\hline 3 & Farizal & 2.95 & 450 & Lurah & $\operatorname{Rp~} 1,000,000$ \\
\hline 4 & Mohamad Azhar & 2.84 & 1300 & Lurah & $\operatorname{Rp~} 2,400,000$ \\
\hline 5 & Bagus Sopyan & 3.11 & 900 & Lurah & $\operatorname{Rp~} 2,900,000$ \\
\hline 6 & Ika Yunsita Pratiwi & 3,00 & 1300 & Lurah & $\operatorname{Rp~} 1,500,000$ \\
\hline 7 & Yulianti Suryani & 3.35 & 900 & Lurah & $\operatorname{Rp~} 1,000,000$ \\
\hline 8 & Yudi Hastomi & 3.24 & 450 & Lurah & $\operatorname{Rp~} 1,800,000$ \\
\hline 9 & Selly Yunis & 3.13 & 450 & Lurah & $\operatorname{Rp} 800,000$ \\
\hline 10 & Teguh Imam Perdana & 3.06 & 900 & Lurah & $\operatorname{Rp~} 800,000$
\end{tabular}

Tabel 4.1 adalah data utama yang diperlukan dalam proses eksperimen yaitu data nama, IPK, daya listrik, penerbit SKTM (salah satu indikator kelengkapan berkas) dan gaji orang tua. Data utama tersebut yang nantinya akan dijadikan parameter oleh algoritma Nä̈ve Bayes dan Support Vector Machine pada saat pengolahan data.

\subsubsection{Perubahan Data ke dalam Bentuk Vektor}

Data yang sudah sesuai dengan parameter yang dibutuhkan untuk penelitian akan diubah ke dalam bentuk vektor guna mempermudah proses kerja algoritma.

Tabel 4.2 Inisialisasi Data Menjadi Nominal Kecil

\begin{tabular}{|l|c|l|c|c|}
\hline IPK & $:$ & $0-2,74$ & $\rightarrow$ & 1 \\
\hline & $:$ & $2,75-3,25$ & $\rightarrow$ & 2 \\
\hline & $:$ & $3,26-4,00$ & $\rightarrow$ & 3 \\
\hline $\begin{array}{l}\text { Gaji Orang } \\
\text { Tua }\end{array}$ & $:$ & $\begin{array}{l}\text { Rp. } 0 \text { - Rp. } \\
2.000 .000\end{array}$ & $\rightarrow$ & 1 \\
\hline & $: \begin{array}{l}\text { Rp. 2.000.001- Rp. } \\
5.000 .000\end{array}$ & $\rightarrow$ & 2 \\
\hline & $:$ & $\begin{array}{l}\text { Rp. 5.000.001- Rp. } \\
10.000 .000\end{array}$ & $\rightarrow$ & 3 \\
\hline Berkas & $:$ & Lengkap & $\rightarrow$ & 1 \\
\hline & $:$ & Tidak Lengkap & $\rightarrow$ & 2 \\
\hline $\begin{array}{l}\text { Rekening } \\
\text { Listrik }\end{array}$ & $:$ & $450 \mathrm{~V}$ & $\rightarrow$ & 1 \\
\hline & $:$ & $900 \mathrm{~V}$ & $\rightarrow$ & 2 \\
\hline & $:$ & $1300 \mathrm{~V}$ & $\rightarrow$ & 3 \\
\hline & $:$ & $2200 \mathrm{~V}$ & $\rightarrow$ & 4 \\
\hline
\end{tabular}

Tabel 4.2 adalah inisialisasi yang penulis tentukan untuk merubah data mahasiswa kedalam bentuk nominal yang lebih kecil.

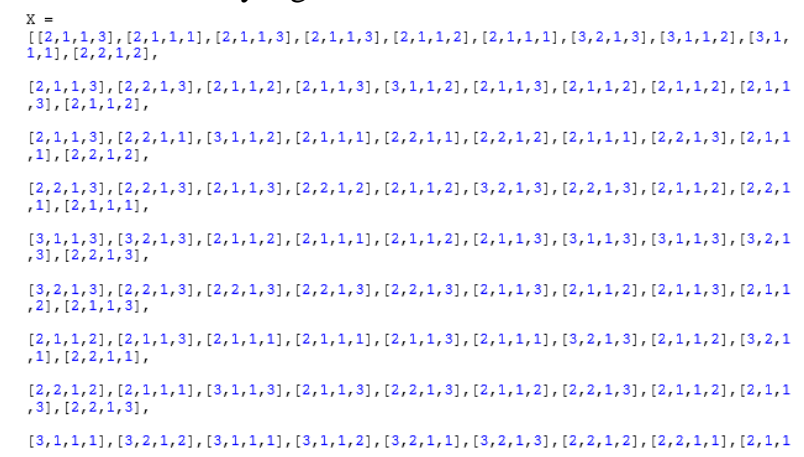

Gambar 4.1 Data yang Telah Diubah Menjadi Bentuk Vektor

Gambar 4.1 adalah data yang sudah diubah ke dalam bentuk vektor dengan urutan [ipk, gaji orang tua, kelengkapan berkas, rekening listrik]. Data mahasiswa yang lulus maupun tidak lulus sebanyak 700 data dan telah dibagi menjadi 10 kelompok, dimana dalam 1 kelompok terdapat 70 data mahasiswa dengan urutan 50 data mahasiswa yang lulus dan 20 data mahasiswa tidak lulus. Pengelompokkan data ini berguna untuk tahap evaluasi akurasi algoritma menggunakan K-fold Cross Validation.

\subsubsection{Pemberian Label Pada Data}

Setelah data diubah kedalam bentuk vektor maka tahap selanjutnya untuk memudahkan proses 
pembelajaran data (learning step) maka data tersebut harus diberikan label. Untuk data mahasiswa yang lulus pemberkasan beasiswa akan dilabeli dengan angka 1, sedangkan untuk data mahasiswa yang tidak lulus pemberkasan beasiswa akan dilabeli dengan angka 0 .

Label data tersebut kemudian dibagi menjadi dua kelompok yaitu kelompok label data train untuk membantu algoritma mempelajari data, dan kelompok label data test untuk mendapatkan hasil akurasi yaitu membandingkan hasil klasifikasi oleh algoritma dengan hasil yang seharusnya. Untuk satu kelompok data dengan jumlah 70 data diberi urutan label 50 data lulus (1) dan 20 data tidak lulus (0). Karena dalam 1 iterasi terdapat 9 kelompok data train maka terdapat 630 label data train, dan 1 kelompok data test sebanyak 70 label data test.

\subsection{Analisis Data Penelitian}

Data telah di verifikasi dan selanjutnya akan masuk ke dalam tahap pengolahan data. Kumpulan data dalam bentuk vektor tersebut akan diolah menggunakan dua algoritma yaitu Nä̈ve Bayes dan Support Vector Machine. Instrumen atau alat yang digunakan oleh peneliti untuk mengaplikasikan bahasa pemrograman python pada algoritma Nä̈ve Bayes dan Support Vector Machine adalah Jetbrains Pycharm 5.0.4.

\subsubsection{Pengolahan Data Menggunakan Algoritma} Nä̈ve Bayes

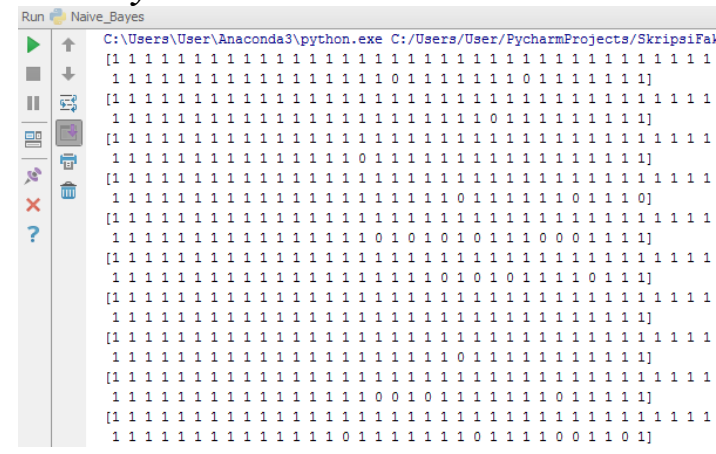

Gambar 4.2 Output Klasifikasi Algoritma Nä̈ve Bayes

\subsubsection{Pengolahan Data Menggunakan Algoritma} Support Vector Machine

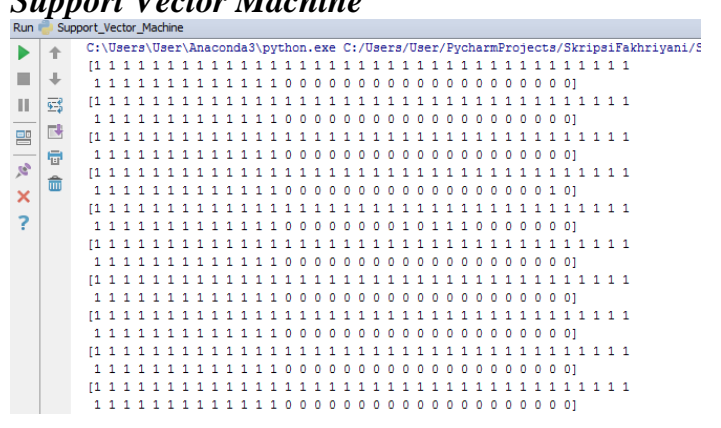

Gambar 4.3 Output Klasifikasi Algoritma Support Vector Machine

\subsubsection{Hasil Akurasi Menggunakan $K$-fold Cross Validation}

Setelah diolah menggunakan algoritma Nä̈ve Bayes dan Support Vector Machine, kedua algoritma tersebut harus dihitung akurasinya menggunakan $K$ fold Cross Validation. Seperti yang sudah dijelaskan di bab sebelumnya $K$-fold Cross Validation berfungsi untuk mencari akurasi dari algoritma dengan membagi data menjadi $\mathrm{k}$ data dan dilakukan sebanyak $\mathrm{k}$ kali. Pada penelitian ini peneliti menggunaka 10 fold yang berarti data akan dibagi menjadi 10 kelompok dan dilakukan iterasi sebanyak 10 kali. Hasil dari akurasi tersebut apabila mendekati 0 maka algoritma tersebut dianggap tidak bagus atau tidak akurat, namun apabila hasil akurasi mendekati 1 atau sama dengan 1 maka akurasi dari algoritma tersebut dapat dikatakan sangat bagus atau sangat akurat.

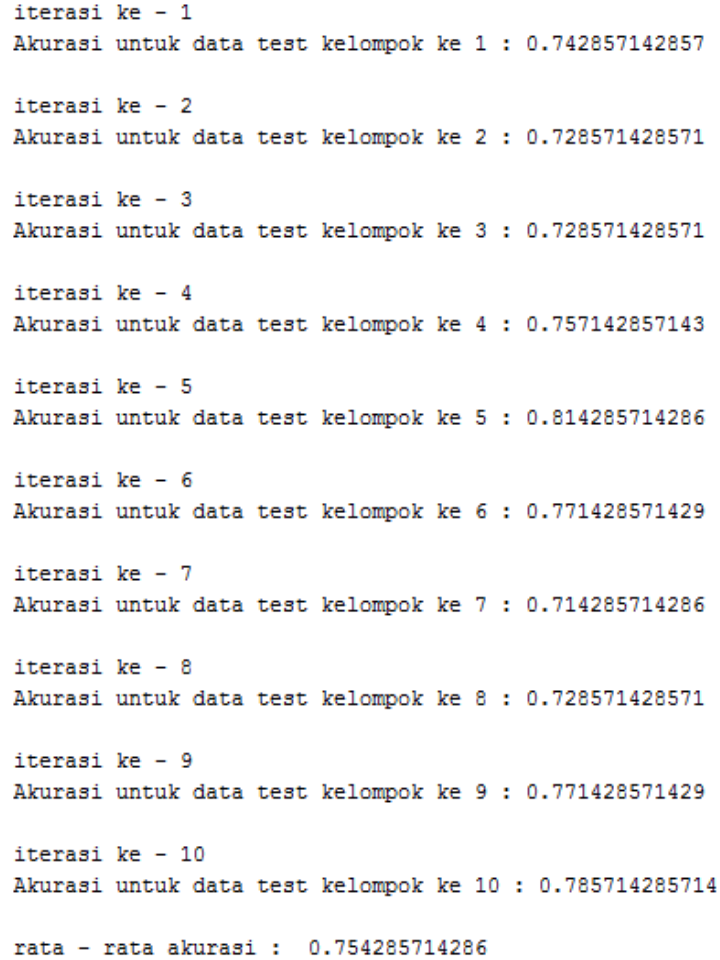

Gambar 4.4 Hasil Akurasi Menggunakan Algoritma Nä̈ve Bayes 


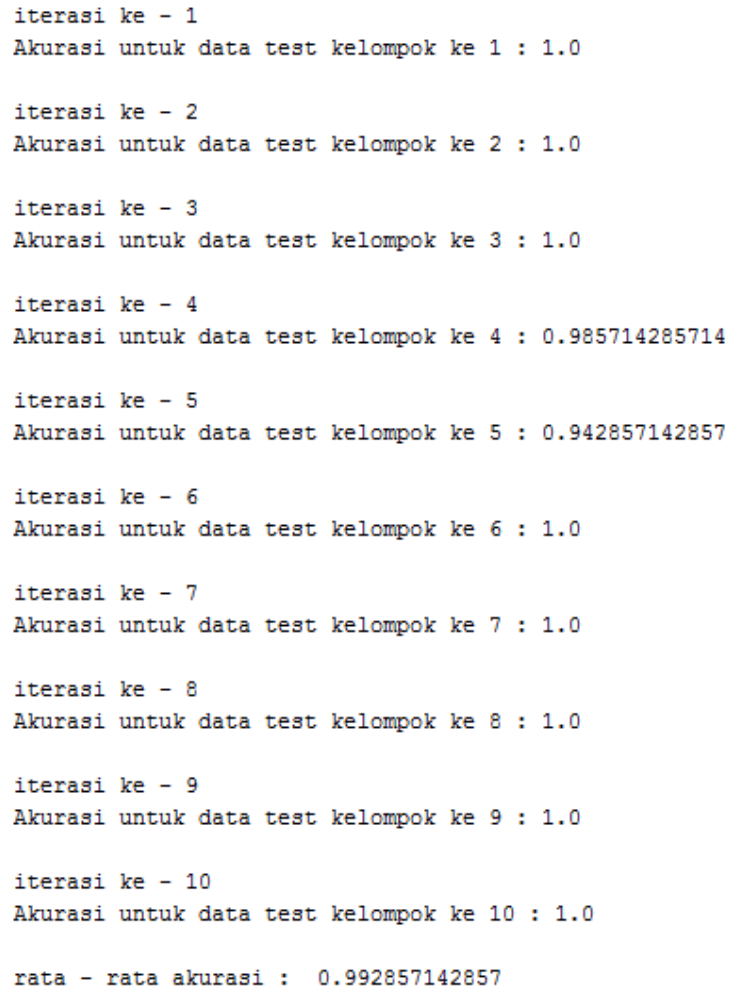

Gambar 4.5 Hasil Akurasi Menggunakan Algoritma Support Vector Machine

\subsection{Pembahasan}

Tabel 4.3 Perbandingan Hasil Akurasi Algoritma Nä̈ve Bayes dan Support Vector Machine

\begin{tabular}{|c|c|c|}
\hline Iterasi & Naïve Bayes & $\begin{array}{c}\text { Support Vector } \\
\text { Machine }\end{array}$ \\
\hline 1 & 0.7428 & 1.0 \\
\hline 2 & 0.7285 & 1.0 \\
\hline 3 & 0.7285 & 1.0 \\
\hline 4 & 0.7571 & 0.9857 \\
\hline 5 & 0.8142 & 0.9428 \\
\hline 6 & 0.7714 & 1.0 \\
\hline 7 & 0.7142 & 1.0 \\
\hline 8 & 0.7285 & 1.0 \\
\hline 9 & 0.7714 & 1.0 \\
\hline 10 & 0.7857 & 1.0 \\
\hline $\begin{array}{c}\text { Rata- } \\
\text { rata }\end{array}$ & 0.7542 & 0.99 \\
\hline
\end{tabular}

Tabel 4.3 adalah tabel perbandingan hasil akurasi algoritma Nä̈ve Bayes dan Support Vector Machine dengan menggunakan $K$-fold Cross Validation. Selanjutnya penulis membandingkan hasil rata-rata akurasi dari kelas eksperimen menggunakan dua algoritma yaitu algoritma Nä̈ve Bayes dan Support Vector Machine dengan akurasi kelas kontrol yaitu nilai data akurat pada kondisi nyata dengan tingkat akurasi 1 atau sempurna.

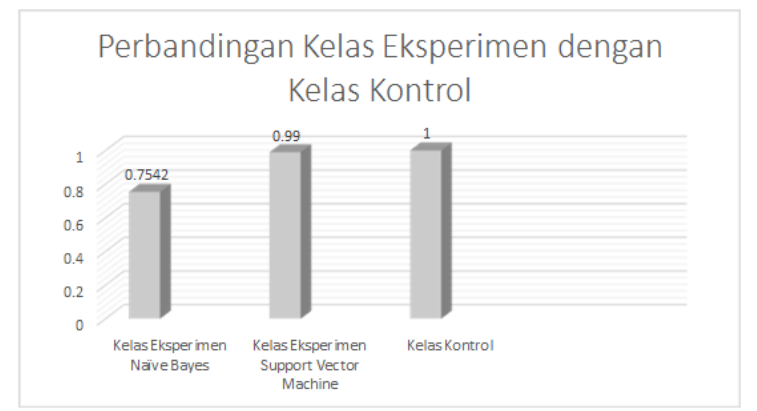

Gambar 4.6 Perbandingan Kelas Eksperimen dengan Kelas Kontrol

Gambar 4.6 adalah diagram batang dari hasil akurasi kelas eksperimen dan kelas kontrol. Hasil akurasi dari kelas eksperimen yang menggunakan algoritma Nä̈ve Bayes sebesar 0.7542. Untuk hasil akurasi dari kelas eksperimen yang menggunakan algoritma Support Vector Machine adalah sebesar 0.99 , sedangkan akurasi yang seharusnya dicapai oleh kedua algoritma tersebut adalah sama dengan akurasi kelas kontrol yaitu nilai data akurat pada kondisi nyata yang seharusnya dicapai dan diberi angka 1. Namun diantara kedua algoritma tersebut yang paling mendekati akurasi kelas kontrol adalah Support Vector Machine dengan tingkat akurasi 0.99 .

\subsection{Aplikasi Hasil Penelitian}

Setelah penelitian dilakukan dan mendapatkan hasil penelitian berupa satu dari dua algoritma yang lebih akurat dalam kasus seleksi kelulusan pemberkasan beasiswa BPP-PPA Fakultas Teknik Universitas Jakarta, penulis berharap penelitian ini dapat berguna untuk penelitian selanjutnya. Aplikasi dari hasil penelitian itu sendiri dapat berupa sebuah program yang dapat menyeleksi berkas secara otomatis baik yang bersifat offline maupun online, sehingga memudahkan proses seleksi berkas beasiswa tersebut. Penulis juga berharap hasil penelitian dapat digunakan untuk pembuatan web beasiswa dimana mahasiswa dapat mengisi dan upload berkas beasiswa secara online kemudian pada saat yang bersamaan data mahasiswa tersebut dapat diseleksi menggunakan algoritma yang telah disimpulkan pada penelitian ini.

\section{Kesimpulan dan Saran \\ 5.1 Kesimpulan}

Kesimpulan yang diperoleh setelah melalui tahap-tahap perbandingan hasil akurasi algoritma Nä̈ve Bayes dan Support Vector Machine adalah :

- Diantara algoritma Nä̈ve Bayes dan Support Vector Machine, algoritma yang lebih akurat untuk seleksi pemberkasan Beasiswa BPP-PPA di Fakultas Teknik Universitas Negeri Jakarta adalah algoritma Support Vector Machine.

- Hasil klasifikasi kedua algoritma tersebut dihitung tingkat akurasinya menggunakan $K$-fold Cross Validation, dengan hasil rata-rata akurasi algoritma 
Nä̈ve Bayes adalah 0.7542 dan hasil rata-rata akurasi algoritma Support Vector Machine adalah 0.99 .

- Baik algoritma Nä̈ve Bayes maupun Support Vector Machine telah mampu menangani proses penyeleksian kelulusan pemberkasan beasiswa BPPPPA Fakultas Teknik Universitas Negeri Jakarta.

- Algoritma Support Vector Machine menghasilkan rata-rata akurasi 0.99 dan mendekati nilai akurasi yang nyata yaitu 1, maka algoritma tersebut dinilai lebih akurat dan direkomendasikan untuk penelitian selanjutnya.

\subsection{Saran}

Penulis memiliki beberapa masukan untuk penelitian selanjutnya yang berhubungan dengan komputerisasi seleksi kelulusan pemberkasan Beasiswa BPP-PPA Fakultas Teknik Universitas Negeri Jakarta, dengan harapan semakin akurat dan tepat sasaran seleksi kelulusan beasiswa tersebut.

- Menambahkan data train, semakin banyak data train maka akan semakin akurat hasil dari klasifikasi.

- Memasukkan fungsi perubahan data ke bentuk vektor pada coding untuk otomatis merubah data kebentuk vektor.

\section{Daftar Pustaka:}

E, Turban dkk. (2005). Decicion Support Systems and Intelligent Systems. Yogyakarta:Andi Offset.

Departemen Pendidikan Nasional. (2005). Kamus Besar Bahasa Indonesia Edisi Ketiga. Jakarta: Balai Pustaka.

Direktorat Jendral Pendidikan Tinggi. (2015). Pedoman Umum Beasiswa Bantuan Biaya Pendidikan Peningkatan Prestasi Akademik (PPA). Direktorat Jendral Pembelajaran dan Kemahasiswaan Kementerian Riset, Teknologi, dan Pendidikan Tinggi.

Fakultas Teknik. 2015. Buku Panduan Penyusunan Skripsi dan Non Skripsi. Fakultas Teknik, Universitas Negeri Jakarta.

Han, Jiawei dkk. (2012). Data Mining Concepts and Techniques, $3^{\text {rd }}$ ed. Waltham, USA: Elsevier Inc.

Hastuti, Khafiizh. (2012). Analisis Komparasi Algoritma Klasifikasi Data Mining untuk Prediksi Mahasiswa Non Aktif. Seminar Nasional Teknologi Informasi dan Komunikasi Terapan, 2(1):242-243.

Kohavi, Ron. (1995). A Study of Cross-Validation and Bootstrap for Accuracy Estimation and Model Selection. International Joint Conference on Artifical Intellegence, 14(2):1137-1145.

Octaviani, Pusphita Anna dkk. (2014). Penerapan Metode Klasifikasi Support Vector Machine (SVM) pada Data Akreditasi Sekolah Dasar
(SD) di Kabupatern Magelang. Seminar Nasional Informatika, 3(4):812.

Prasetyo, Eko. (2012). Data Mining : Konsep dan Aplikasi menggunakan MATLAB, 1 st ed. Yogyakarta:Andi Offset.

Prasetyo, Eko. (2014). DATA MINING - Mengolah Data menjadi Informasi Menggunakan Matlab. Yogyakarta: Andi Offset. 